\title{
Research on The Frame of Reference with The Downward Displacement of The Posterior Leaflet and Anterior Leaflet of Tricuspid Valve in Children by Ultrasound
}

\author{
Jun-jian $\mathrm{Yu}^{1}$, Kang Liu ${ }^{1}$, Rong-cheng Tian ${ }^{1}$, Xuehong Zhong ${ }^{1}$, and Bei $\mathrm{Li}^{1}$ \\ ${ }^{1}$ Affiliation not available
}

June 10, 2021

\begin{abstract}
To investigate the frame of reference with the downward displacement of the posterior leaflet and anterior leaflet of tricuspid valve in children by ultrasound.The downward degree of anterior and posterior tricuspid valve was evaluated with tricuspid annulus and coronary sinus as reference structures under ultrasound, and the position of tricuspid regurgitation orifice was shown by color ultrasound. Color Doppler flow imaging showed that the position of tricuspid regurgitation orifice moved down obviously in all 42 children. One case showed $2.2 \mathrm{~cm}$ from the root of the anterior valve to the tricuspid annulus in the twochamber and four-chamber view of the apical right heart. Color Doppler can show that the position and direction of tricuspid regurgitation orifice are obviously deviated to the anterolateral side. The obvious deviation of the tricuspid regurgitation orifice to the anterolateral direction may be an ultrasonic sign for diagnosing the downward displacement of the anterior tricuspid valve in children.
\end{abstract}

\section{Hosted file}

Research on The Frame of Reference with The Downward Displacement of The Posterior Leaflet and Anterior available at https://authorea.com/users/419139/articles/525726-research-on-the-frame-ofreference-with-the-downward-displacement-of-the-posterior-leaflet-and-anterior-leafletof-tricuspid-valve-in-children-by-ultrasound 